\title{
The Effectiveness of Targeting Social Transfer Programs in Indonesia
}

\author{
Annissa Sri Kusumawati ${ }^{1}$ \\ Ministry of National Development Planning/ Bappenas - Indonesia
}

\begin{abstract}
This paper assesses the performance of method targeting and implementation error of social transfer programs in Indonesia, which consists of Raskin, in-kind transfer; Program Keluarga Harapan (PKH), a conditional cash transfer; Program Indonesia Pintar (PIP), scholarship program; and Program Indonesia Sehat (PIS), free health insurance for the poor and vulnerable. The logit model of exclusion and inclusion errors shows the drivers of probability error in targeting these four kinds of social transfer programs. The finding shows error in the implementation that relies heavily on urban-rural differences and legal identity ownership rather than the role of government employees. Measuring the performance of miss-targeting is needed to improve the effectiveness of social transfer programs on achieving their goals. The analysis of targeting performance suggests caution in employing a mechanism of the delivery program to improve the implementation of the targeting program to promote more social safety net rather than in-kind transfer and cash transfer as well as to re-evaluate the identification requirement for receiving social benefits to reach the beneficiaries from the extreme poor.
\end{abstract}

Keywords: targeting social transfer programs, vulnerable poor, urban-rural differences, legal identity, the role of a government employee, social safety net, cash transfer, in-kind transfer, Indonesia

\footnotetext{
${ }^{1}$ Annisa Sri Kusumawati is a Planner Staff at the Directorate for Poverty Alleviation and Social Welfare, Ministry of National Development Planning/Bappenas RI. Email: annissa.kusumawati@bappenas.go.id
} 


\title{
The Effectiveness of Targeting Social Transfer Programs in Indonesia
}

\author{
Annissa Sri Kusumawati
}

\section{Introduction}

The social protection policy for the poor does not directly eliminate poverty, but it lets the poor manage the risks of income shocks and enables capacity building towards inclusive growth (Holzmann \& Jorgensen, 1999; Norton, Conway, \& Foster, 2001). The social transfer is a part of the social protection policy that focuses on recovery from income shocks and is the fastest way to reduce poverty. Further, the trend of a national budget for social transfer programs has increased every year. Still, the evaluation measured by the output program rather than measuring the targeting's performance.

The urgency to evaluate social protection programs due to the inappropriate design of the social transfer program and error in targeting implementation might result in dependency of the beneficiaries on the grants (Slater, Holmes, Farrington, \& Harvey, 2007). For example, an inappropriately designed program is when the eligibility criteria of the education program allow all households, which is the only household with children, because the grant is more meaningful for the school-age population. Also, error targeting in implementation emphasizes on external factors, such as process validation and the verification of recipients' data involving family members as beneficiaries. These wrong selection influence the behavior of the recipients for being a moral hazard to the aid, since they do not want to make any changes themselves to emancipate the condition of poverty. Therefore, measuring the targeting effectiveness of the social transfer program will help assess how to minimize the miss-targeting of beneficiaries (Devereux et al., 2017; SabatesWheeler, Hurrell, \& Devereux, 2015).

The analysis will focus on the drivers' miss-targeting of each social transfer programs in Indonesia by identifying the probability of under coverage for eligible beneficiaries (exclusion error) and leakage to non-eligible beneficiaries (inclusion error). Thus, this research conducts an empirical study to answer these following questions:

1. Is there an increase in probability miss-targeting caused by inappropriate formulae of the targeting method?

2. Do urban-rural differences, working as government employees, and legal identity administration increase exclusion error and decrease inclusion error in the implementation?

3. To what extent the determinants of miss-targeting could improve the targeting effectiveness in social transfer programs?

The expected result is that the performance of the design method on targeting is sufficient, focusing on instances of implementation errors. These findings would help the assessment with how to push effective targeting on improving the program's design and implementation.

\section{Literature Review}

Evaluation regarding targeting performance in the poverty alleviation programs is debatable when the production of output programs achieved. Ravallion (2009) argued that assessment is enough for only consider the result of program 
outcome rather than bringing up miss-targeted in the antipoverty programs. Meanwhile, other studies have discussed the importance of measuring the effectiveness of targeting in social transfer programs (Coady, Grosh, \& Hoddinott, 2004; Devereux et al., 2017; Leite, Stoeffl, \& Kryeziu, 2008).

A study mention, "... describe targeting errors in implementation, meaning that the predefined rules for identifying and registering eligible beneficiaries are not fully met in practice" (Devereux et al., 2017). It suggests that miss-targeting is occurred not only caused by the design of targeting (on determining the eligibility criteria), but targeting error also could happen in the implementation, for example, in the process validation and verification. The drivers of implementation error are:

1. having a close relationship with a person who has an official position or works in the government sector tends to get a more significant opportunity for getting the aid (Sharp, K., 1997; Farrington, J., Sharp, K., \& Sjoblom, D., 2007).

2. Sharif (2009) suggests that people in urban poor tend to excluded from the program. The argument is urban poverty has higher extreme poor rather than rural areas.

3. The government's program requires a legal identity to access social welfare benefits (World Bank, 2016).

\section{Overview of The Targeting Social Transfer Programs in Indonesia}

\subsection{The Targeting Method of Social Protection Database}

Data regarding the beneficiaries of targeted social welfare programs by name and by address in Indonesia is known as the universal database (UDB). In practice, the targeting design uses a mixed-method between community-based targeting and proxy means test/PMT (V. Alatas, Banerjee, Hanna, Olken, \& Tobias, 2012). The mechanism of targeting started in a community-based approach to predict the bottom income/expenditure of $40 \%$ of the population by the Pendataan Program Perlindungan Sosial (PPLS) survey. Conducting a PPLS survey is more costeffective than conducting a PPLS census for about 250 million people, i.e., Indonesia's entire population (V. Alatas et al., 2012; Hanna \& Karlan, 2016). Then, PMT weights the beneficiaries in the PPLS, based on several well-being statuses, such as asset ownership, standards of living (housing, electricity, clean water, and sanitation), member of household, education, employment status, and the ratio of marginal areas or indeks kesulitan geografis (Government of Indonesia, 2017). This weighted PMT formula has ranked among the poor, and it is referred to as the UDB for social protection programs.

\subsection{Design Program of Social Transfer}

Indonesia's strategy on poverty reduction involves the social protection program that covers individuals, families, or households, and communities to manage their socio-economic risks and vulnerability. They can fulfill the minimum needs based on the Law of the Republic of Indonesia, Number 11, 2009, about social welfare (Government of Indonesia, 2009). Article 14 states that those kinds of social protection apply for social safety nets or social transfers program.

There are four main social transfer programs in Indonesia, namely subsidy Beras Masyarakat Miskin (Raskin), Program Keluarga Harapan (PKH), Program Indonesia Pintar (PIP), and Program Indonesia Sehat (PIS). According to the Indonesian National Team for the Acceleration of Poverty Reduction (TNP2K), the descriptions of those social transfer programs are as follows: 
1. Raskin program, known as food subsidy or in-kind transfer program, has a goal of increasing the calorie intake for poor households to prevent stunting for the next generation. The beneficiaries are ratified by the Ministry of Social Affairs, while the institution is responsible for delivering in-kind transfer is Bulog;

2. Program Keluarga Harapan (PKH) or conditional cash transfer (CCT). The purpose is to provide better access to education and health for the poor from households that have pregnant women or babies and school-age children. It is designed only for five years of cash transfers to avoid dependence on the grants. After that, they will transfer to other social assistance programs, such as KUBE, a financial inclusion program which is a part of a graduation program. The provider is the Ministry of Social Affairs for targeting mechanism, while the delivery has cooperation with PT Pos (a state-owned company in postal services) and banks;

3. Program Indonesia Pintar (PIP), known as the student scholarship program for the poor. Its objective is to build equal opportunities for educational services. The implementation is managed by the Ministry of Education and Ministry of Religious Affairs with cooperation with schools and the local government;

4. Program Indonesia Sehat (PIS) provides free health insurance for the poor, which is a part of the social security program for getting healthcare services for everyone or universal health coverage. The provider is Healthcare BPJS, an agency of national health insurance.

\subsection{The Classification of Miss-Targeting Program}

The classification of targeting errors by Devereux et al. (2015), as depicted in Figure 1, consists of exclusion error, the eligible population who are not receiving the program, and inclusion error, the non-eligible population who enrolled in the program. The decision of eligibility criteria based on poverty or coverage program is quite debatable. This paper will use a previous study by Tohari, Parsons, \& Rammohan (2017) that explains how the government of Indonesia decides the coverage of poverty programs. Thus, the threshold of correct targeting is to reach the vulnerable poor in the UDB that consists of the poor, below the poverty line, near-poor, bottom of the 25 percentile, and the vulnerable poor, the bottom $40 \%$ of the lowest income population.

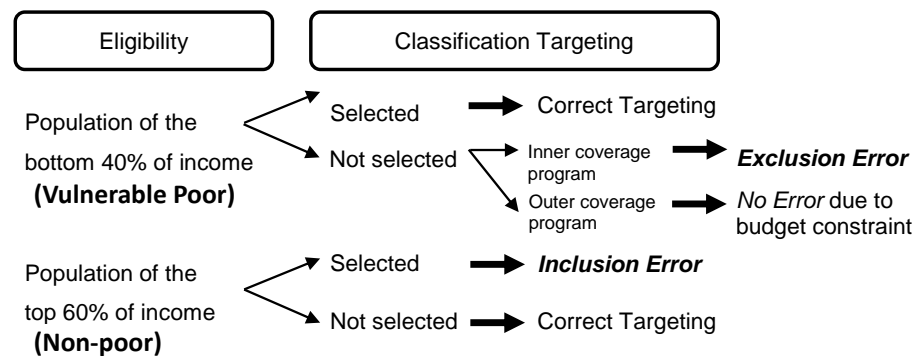

Figure 1. Classification of Targeting Error

However, in Indonesia, the target of the beneficiaries' program is restricted by budget constraints, so not all the vulnerable sparse population can receive the grants. It affects the classification of miss-targeting among the vulnerable poor. Not selected as the recipients of the program means exclusion error if the percentage is not included in the inner coverage program, while the vulnerable poor in the outer coverage program categorized as no error targeting due to budget constraints. 
Table 1 below provides a comparison between the coverage of social transfer programs and the exact poor beneficiaries based on an expenditure approach, while the targeting beneficiaries are the vulnerable poor or people in the bottom $40 \%$ of income. As an illustration, if correct targeting for vulnerable poor in the Raskin program does not achieve $22.23 \%$, it means that there is an exclusion error from the amount of coverage program minus the correct targeting of vulnerable poor who receive Raskin program. Meanwhile, the helpless poor between $22.23 \%$ up to $40 \%$ who not selected as recipients of the Raskin program not categorized as an exclusion error but as no error in targeting because the plan does not cover it. On the other hand, an inclusion error occurs when non-poor people in the top $60 \%$ of income selected as recipients of social transfer programs.

Table 1. Data on Poor Percentage and the Coverage Programs

\begin{tabular}{llccc}
\hline \multicolumn{2}{l}{ Programs Level } & Poor Percentage & \multicolumn{2}{c}{ Coverage Program } \\
\hline Raskin & Household & $8.06 \%$ & $15,600,000$ & $(22.23 \%)$ \\
PKH & Household & $8.06 \%$ & $10,000,000$ & $(14.25 \%)$ \\
PIP & Student & $11.26 \%$ & $19,700,000$ & $(35.35 \%)$ \\
PIS & Individual & $9.82 \%$ & $92,400,000$ & $(34.96 \%)$ \\
\hline
\end{tabular}

\section{Conceptual Framework}

The study regarding the targeting design of transfer programs in Indonesia by Alatas et al. (2012) shows the experimental design to compare which method would provide the best results on targeting. Therefore, this study would examine which variables of the targeting method are still weak to minimize miss targeting or determine eligibility criteria in each of the social transfer programs. The variables categorized into household characteristics and the standard of living. The hypothesis will follow the logical directive relationship of food expenditure as a control variable to miss-targeting, both exclusion, and inclusion error. For example, the increase of food expenditures or the welfare of beneficiaries is related to the probability exclusion error going up and the inclusion error going down. Therefore, better education in the household characteristic variable has a similar direction with the relationship of food expenditure and its dependent variables.

Meanwhile, the rest of the variables in the household characteristic category, such as the number of members in a household, gender, elderly, disability, and lowwage employment, have the opposite effect. It implied when many rejected the hypothesis, which means a lack of PMT formula on the design program. These hypotheses will answer whether there is an error in the targeting design to recommend some improvement on the PMT method of targeting the beneficiaries of social transfer programs.

On the other hand, besides those above variables, implementation error variables are consisting of a government employee, urban, and identity ownership. The first, government employee variable, could be the local leaders or person who works in government service, such as the head of villages, including the staffs based on Alatas et al. (2012). Second, social transfer programs in Cameroon show the potential of urban-rural differences in the PMT formula and argue that it provides a better fit estimation on targeting (Stoeffler, Mills, \& Del, 2016). The last variable of error implementation is legal identity, especially the birth certificate, which has 
an indirect connection to promoting child rights and protection in terms of accessibility to education, health, and public services (Dunning, Gelb, Raghavan, \& Dc, 2015; Hamilton et al., 2014). Other studies have also argued the importance of legal identity, so it is not excluded from poverty programs and avoid duplicate grants for the same recipient, the conditional cash transfer program in Indonesia, Bangladesh, and some countries in Latin America, such as Bolivia, Guatemala, and Ecuador (Harbitz \& Tamargo, 2009; Hossain, 2010; Sumner, 2015).

\section{Methodology}

This research will use maximum likelihood estimation through the logit model by Stoeffler et al. (2016) to measure the probability of individuals being excluded from or included in each of the social transfer programs. The difference of this study with the model, as mentioned above, is determining the independent variables. Stoeffler et al. (2016) are only describing the determinants of exclusion and exclusion errors based on household characteristics and the standard of living on behalf of the PMT criteria as a method of targeting, while this study adds three variables as the drivers of implementation errors in targeting.

The logit model is:

$$
Y_{i j}^{L M}=\beta_{0}+\beta_{1} X_{i j}+\varepsilon_{i j}
$$

where,

$Y_{i j} \quad$ is the dependent variable of binomial individual $i$ (value 1 if inclusion error, value 0 if otherwise) excluded from or included in social transfer program $j$

$X_{i j} \quad$ represents independent variables of beneficiaries $i$ characteristics in the social transfer program $j$

$\varepsilon_{-} i \quad$ is the error term

The level sample of dependent variables for exclusion and inclusion errors in Raskin and PKH are households, while for PIP, it is students between the ages of 7 and 18 years. The PIS conducted at an individual level. It means there are four equations for exclusion errors in the Raskin, PKH, PIP, and PIS program, as well as four equations for inclusion errors.

The independent variables consist of the following:

1. The binary of urban-rural differences (value 1 if in the urban area; value 0 if in the rural area).

2. The binary of relationship with the administrator of government (value 1 if there is a member in a household who works in government administrator, military or social worker; value 0 if otherwise).

3. The binary of legal identity membership, such as birth certification, identity card, and family card (value 1 if legal identity is available; value $O$ if otherwise).

4. The log value of food expenditure per capita.

5. The number of household members.

6. The binary of gender regarding the head of the household (value 1 if the head of the family is women; value 0 if otherwise).

7. The binary of the elderly as the head of the household (value 1 if the age of the head of the household is age $>64$ years old; value 0 if otherwise).

8. The degree of disability (value 1 until 8: the number of different types of disability from sight, hearing, walking, hand movement, thinking, emotional communication until self-care; value $O$ if no disable). 
9. Higher education of the head of the household (continues value of the length of school from 0 until 23 for the head of the household).

10. The binary of low-wage employment of the head of the household, value 1 if working as an employee in the agriculture and informal sector for above 15 years of age, and value 0 if otherwise.

11. The binary of proper asset/house ownership in a household (value 1 if having a house with the size $>=36$ square and suitable roofs, walls, floors, and value $\mathrm{O}$ if otherwise).

12. The binary of proper electricity in a household (value 1 if the source electricity from PLN as an official provider with the power above 900 watts, and value 0 if otherwise).

13. The binary of proper clean water in a household (value 1 if the household has a proper source of clean water and far enough from domestic waste; and value $\mathrm{O}$ if otherwise).

14. The binary of proper sanitation in a household (value 1 if the household has proper sanitation, including the closet type and domestic waste dumps and value 0 if otherwise).

Table 2. Summary descriptive of dependent and independent variables

\begin{tabular}{|c|c|c|c|c|c|}
\hline Variable & Obs & Mean & Std. Dev. & Min & Max \\
\hline er_raskin & 60,009 & 0.4385842 & 0.4962179 & O & 1 \\
\hline er_pkh & 38,371 & 0.7835605 & 0.4118226 & 0 & 1 \\
\hline er_pip & 114,826 & 0.749909 & 0.433067 & o & 1 \\
\hline er_pis & 433,794 & 0.576022 & 0.494187 & o & 1 \\
\hline ir_raskin & 185,532 & 0.2609685 & 0.4391639 & o & 1 \\
\hline ir_pkh & 185,532 & 0.0503094 & 0.2185832 & o & 1 \\
\hline ir_pip & 134,813 & 0.1294015 & 0.335645 & 0 & 1 \\
\hline ir_pis & 641,762 & 0.2760042 & 0.4470192 & 0 & 1 \\
\hline \multicolumn{6}{|l|}{ Implementation variables } \\
\hline Urban & $1,131,825$ & 0.4245 & 0.4942 & 0 & 1 \\
\hline Government_employee & $1,104,375$ & 0.0949 & 0.2930 & 0 & 1 \\
\hline Identity & $1,131,825$ & 0.9177 & 0.2748 & 0 & 1 \\
\hline \multicolumn{6}{|l|}{ Household characteristics } \\
\hline Food_exp & $1,131,825$ & $536,539.9$ & 308,196 & $45,591.84$ & $14,400,000$ \\
\hline Log(food_exp) & $1,131,825$ & 13.0514 & 0.5297 & 10.8116 & 16.4830 \\
\hline HHmember & $1,131,825$ & 4.6151 & 1.8912 & 1 & 30 \\
\hline HeadHH_education & $1,131,825$ & 7.8736 & 4.4449 & 0 & 23 \\
\hline HeadHH_employment & $1,128,982$ & 0.2572 & 0.4371 & o & 1 \\
\hline HeadHH_woman & $1,131,825$ & 0.1126 & 0.3161 & 0 & 1 \\
\hline HeadHH_elderly & $1,131,825$ & 0.1719 & 0.3773 & 0 & 1 \\
\hline HeadHH_disability & $1,131,825$ & 0.0736 & 0.4492 & o & 8 \\
\hline \multicolumn{6}{|l|}{ Standard of living } \\
\hline Proper_housing & $1,131,825$ & 0.1814 & 0.3854 & 0 & 1 \\
\hline Proper_electricity & $1,131,825$ & 0.1345 & 0.3412 & o & 1 \\
\hline Proper_water & $1,131,825$ & 0.5513 & 0.4974 & 0 & 1 \\
\hline Proper_sanitation & $1,131,825$ & 0.6525 & 0.4762 & 0 & 1 \\
\hline
\end{tabular}


The data of dependent and independent variables come from Indonesia's socio-economic survey, known as Susenas, conducted in 2018. Further, Table 2 depicts the descriptive statistics of all variables in this model. The sample of Susenas 2018 represents $1,131,825$ observations, while the exclusion error is $40 \%$ of the sample, and inclusion error is $60 \%$ of the sample with additional eligibility criteria for each program. The mean data on Table 2 shows that the probability of the exclusion error for all the transfer programs is higher than the inclusion error.

\section{Results and Discussion}

\subsection{Drivers of Exclusion Error}

The drivers of exclusion errors in Table 3 show variables that classified into two categories, namely, error by implementation and error by design. Most of the proximate determinants have a robust relationship with the exclusion error. The analyses of urban-rural conditions in all social transfer programs have significantly increased the exclusion error for the poor who live in urban areas. Especially for the Raskin program with the highest probability, it is consistent with other studies that regressive participation occurs in urban areas and equally distributed in rural areas for food subsidy programs (Satriawan \& Shrestha, 2018).

On the other hand, the positive and significant probability of members of vulnerable poor households who work as government administrators, military, and social workers are more likely to be excluded from Raskin, PKH, and PIP programs, except for the PIS program. The PKH program has the highest probability compared to other programs and notes the tendency that people who have jobs in the government sector counted as non-inferior, and the PIS program through a noncash transfer for giving free health insurance is more likely to have a better implementation. Surprisingly, it rejects the hypothesis about government employees, such as the head of villages and staffs as representatives of local leaders or decision-makers' figure in the community who can affect the decrease of exclusion error. In contrast, this model shows vice versa. This finding is in line with the previous study regarding the role of local leaders or official positions in the government sector, not affecting the miss-targeting by V. Alatas et al. (2019). Further, legal identity ownership is more likely to decrease the probability of exclusion error in all social transfer programs. Those three implementation variables of targeting affect the likelihood of vulnerable poor for not receiving the application, which has a positive association to the urban areas and to a household who has a member working in the government sector, and negative association to the head of household who has legal identity respectively.

Regarding individual household determinants, most social transfer programs have already considered some PMT indicators, such as food expenditures, the number of household members, education, and employment of the head of the household in each program's design. Nevertheless, the gender variable increases the probability of exclusion errors for the PKH and PIP programs. Meanwhile, the elderly age variable increases the likelihood of exclusion error for the PKH, PIP, and PIS program. Furthermore, the disability variable in the Raskin program proves to be insignificant. On the other hand, the PMT method for the standard of living variables in the probability of exclusion error mostly provides a better estimation on targeting, except clean water indicator in $\mathrm{PKH}$ program proves to be insignificant, and the PIS program shows negative probability. Due to these results, most variables in the design are in line with the hypothesis. It suggests that the 
method of the PMT formula could be admitted as well-designed targeting to determine the condition of the poor.

Table 3. Determinants of Exclusion Error for the Vulnerable Poor within Coverage Program

\begin{tabular}{|c|c|c|c|c|}
\hline Selection by Program & Raskin & PKH & PIP & PIS \\
\hline \multicolumn{5}{|c|}{ Sample of Vulnerable Poor within Coverage Program } \\
\hline \multicolumn{5}{|l|}{ Error by implementation } \\
\hline Urban & $0.540^{* * * *}$ & $0.068^{* * *}$ & 0.135 **** & $0.036^{* * * * *}$ \\
\hline Administrator_government & $0.133^{*} * * *$ & 0.658 6 ***** & $0.251^{* * * * *}$ & -0.007 \\
\hline Identity & $-0.567^{* * * *}$ & $-1.880^{* * * * *}$ & $-0.931^{* * * *}$ & $-1.565^{* * * *}$ \\
\hline \multicolumn{5}{|c|}{ Error by design: Household characteristic } \\
\hline Log_food_expenditure & $0.178^{* * * *}$ & $0.242^{* * * *}$ & $0.284^{* * * * *}$ & $0.216^{* * * *}$ \\
\hline HHmember & $-0.025^{* * * *}$ & $-0.210^{* * * *}$ & $-0.028^{* * * *}$ & $-0.033^{* * * *}$ \\
\hline HeadHH_education & $0.054^{* * * *}$ & $0.047^{*} * * *$ & $0.022^{* * * *}$ & $0.035^{* * * *}$ \\
\hline HeadHH_employment & $-0.147^{* * * *}$ & $-0.053^{*}$ & $-0.040^{* * * *}$ & -0.009 \\
\hline HeadHH_woman & $-0.105^{* * * *}$ & $0.082^{* * *}$ & $0.051^{*} *$ & $-0.042^{*} * *$ \\
\hline HeadHH_elderly & $-0.157^{* * * *}$ & O.194***** & $0.072^{* * * *}$ & $0.024 * * * *$ \\
\hline HeadHH_disability & -0.029 & $-0.051^{* * *}$ & $0.078^{*} * * *$ & $-0.032^{*} * *$ \\
\hline \multicolumn{5}{|c|}{ Error by design: Standards of living } \\
\hline Proper_housing & $0.223^{*} * *$ & $0.618^{* * * * *}$ & $0.321^{* * * * *}$ & $0.612^{* * * *}$ \\
\hline Proper_electricity & $0.593^{* * * *}$ & $0.647^{*} * * * 6$ & $0.436^{* * * * *}$ & $0.346^{* * * *}$ \\
\hline Proper_water & $0.117^{* * * * *}$ & 0.035 & $0.073^{*} * * *$ & $-0.042^{*} * *$ \\
\hline Proper_sanitation & $0.198^{* * * *}$ & $0.251^{* * * * *}$ & $0.134^{* * * * *}$ & $0.067^{*} * * *$ \\
\hline _cons & $-2.397^{* * * *}$ & 0.628 & $-1.804^{* * * *}$ & $-1.152^{*} * * *$ \\
\hline Number of observations & 57,636 & 36,761 & 113,129 & 425,390 \\
\hline
\end{tabular}

\subsection{Drivers of Inclusion Error}

Table 4 presents the determinants of inclusion errors in the sample of noneligible beneficiaries for four different types of social transfer programs in Indonesia. All the variables for implementation error show consistent results and are highly significant to the inclusion error, except the government employee variable in the PIS program. Living in urban areas and having a government employee as a member of the household decreases the probability of inclusion error. Regarding the condition of urban-rural poverty, the gap between eligible and non-eligible beneficiaries based on income inequality in urban communities is more likely higher than in rural communities (Akita \& Pirmansah, 2011; Tjiptoherijanto \& Remi, 2001), so the probability inclusion error in urban areas tends to be lower than in rural areas. It also applies to the government employee variable that affects the lower probability of inclusion error.

Interestingly, it is not significant to the PIS program. In contrast, legal identity ownership tends to increase the probability of inclusion error. Based on the 
analysis of the three implementation variables of leakage targeting, only the PIS program is well implemented in terms of not being affected by the government employee indicator, whether the household has a member working in the government sector or not. These results of inclusion error form a mirror reflection of the results of exclusion error with a different association so that the inclusion error models are strengthening the exclusion error models.

Overall, the design of the PMT method for targeting social transfer in Indonesia has already considered the eligibility criteria of each design program, household characteristic, and standard of living. The most important consideration is the indication error by the implementation, which has a high probability of inclusion error and significance. High exclusion error leads to poor allocation of poverty reduction budget, and the effectiveness of alleviating poverty not maximized. Similarly, high inclusion error results in the ineffective implementation of social transfer programs.

Table 4. Determinants of Inclusion Error among Non Poor Population

\begin{tabular}{|c|c|c|c|c|}
\hline Selection by Program & Raskin & PKH & PIP & PIS \\
\hline \multicolumn{5}{|c|}{ Sample of Non-Poor Population } \\
\hline \multicolumn{5}{|l|}{ Error by implementation } \\
\hline Urban & $-0.959^{* * * *}$ & $-0.276^{* * * *}$ & $-0.285^{* * * *}$ & $-0.117 * * *$ \\
\hline Administrator_government & $-0.472^{*} * * *$ & $-0.835^{* * * *}$ & $-0.469^{* * * *}$ & -0.014 \\
\hline Identity & $0.204^{* * * *}$ & $1.748^{*} * * *$ & $0.487^{*} * *$ & $1.139^{* * * *}$ \\
\hline \multicolumn{5}{|c|}{ Error by design: Household characteristic } \\
\hline Log_food_expenditure & $-0.593^{*} * * *$ & $-0.896^{* * * *}$ & $-0.633^{*} * *$ & $-0.440^{*} * *$ \\
\hline HHmember & $0.040^{*} * * *$ & $0.311^{* * * * *}$ & $0.041^{* * * *}$ & $0.029^{* * * *}$ \\
\hline headHH_education & $-0.107^{* * * *}$ & $-0.110^{* * * *}$ & $-0.075^{* * * *}$ & $-0.064 * * *$ \\
\hline HeadHH_employment & $0.183^{* * * *}$ & $0.238^{*} * * *$ & $0.111^{* * * *}$ & $0.153^{* * * *}$ \\
\hline HeadHH_woman & $0.187^{* * * *}$ & -0.029 & -0.013 & $0.114^{* * * *}$ \\
\hline HeadHH_elderly & -0.008 & $-0.385^{* * * * *}$ & $-0.199^{*} * *$ & $-0.023 * * *$ \\
\hline HeadHH_disability & 0.017 & $-0.111^{* * * *}$ & $-0.062^{* *}$ & $0.037^{* * * *}$ \\
\hline \multicolumn{5}{|c|}{ Error by design: Standards of living } \\
\hline Proper_housing & $-0.096^{*} * * *$ & $-0.611^{* * * *}$ & $-0.331^{*} * * *$ & $-0.573^{*} * *$ \\
\hline Proper_electricity & $-0.959^{* * * *}$ & $-1.060^{* * * *}$ & $-0.625^{* * * *}$ & $-0.309^{* * * *}$ \\
\hline Proper_water & $-0.215^{* * * *}$ & $-0.17 \mathrm{O}^{*} * * *$ & $-0.119^{* * * *}$ & $-0.038 * * *$ \\
\hline Proper_sanitatition & $-0.296^{* * * *}$ & $-0.430^{* * * *}$ & $-0.149^{* * * *}$ & $-0.127 * * *$ \\
\hline -cons & $8.182^{* * * *}$ & $7.665^{* * * *}$ & $6.970^{* * * *}$ & $4.555^{* * * *}$ \\
\hline Number of observations & 175,082 & 175,082 & 132,003 & 623,744 \\
\hline
\end{tabular}

\subsection{Analysis of Miss-Targeting Performance and Coverage Program}

The actual performance of targeting error in the four kinds of social transfer programs based on Susenas Data in 2018 presents different results (see Figure 2). 
The doughnut chart shows the social transfer program has a higher percentage in exclusion error, except for the Raskin program. Interestingly, the actual recipients could be count as the addition between correct targeting for people in the bottom $40 \%$ of income and inclusion error for people in the top $60 \%$ of revenue.

The actual recipients of the Raskin program are about $35 \%$. Meanwhile, the coverage is only $22 \%$. It indicates the food subsidy distributed to many more recipients than the targeted beneficiaries. PKH program has actual recipients. About $9 \%$ compared to the target of the application is $14 \%$; it suggests the difficulties to reach the poorest.

Moreover, the PIP program only delivers $17 \%$, or only a half from the target of the program is $35 \%$. There is an indication of low accountability if the budget still disbursed. The last is the PIS program, which has $31 \%$ actual recipients compared to $35 \%$ of coverage programs. It is more likely has difficulties in fulfilling the quota of the poor beneficiaries.

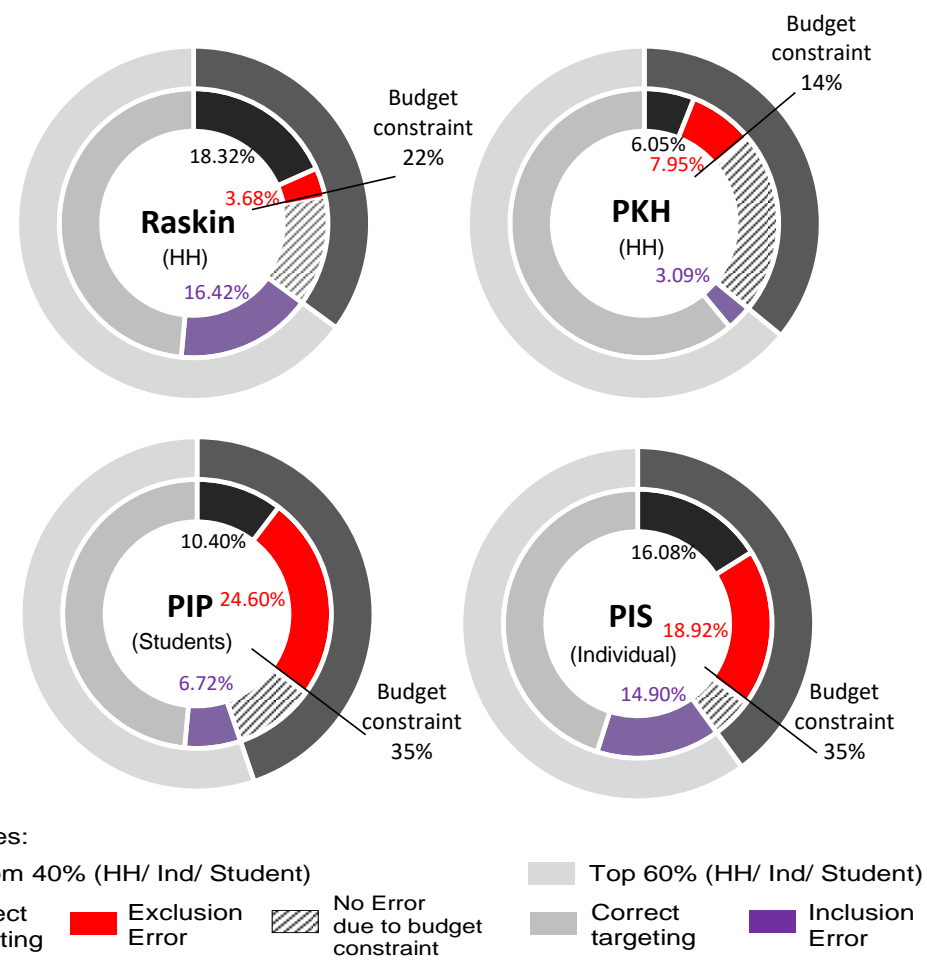

Figure 2. Actual Miss-Targeting Social Transfer Programs in 2018

Source: Susenas (2018)

Furthermore, exclusion and inclusion error in the implementation of social transfer programs indicates the low effectiveness of program targeting. The pattern of exclusion and inclusion error of each program in Figure 2 is not clearly defined. Additional eligibility criteria reflect small inclusion errors in PKH and PIP programs on determining the recipients, but it creates a high exclusion error as well. However, the mechanism of the delivery program is also affecting the misstargeting. The mechanism of in-kind transfer in the Raskin program leads to 
exceeding actual recipients. Then, the challenge of delivering conditional cash transfers to reach the most mediocre results in higher exclusion error.

On the other hand, an indication of low accountability in the PIP program could not be answered by this model due to the limitation variable of the supply side, such as the involvement school and teacher, which might affect the process of targeting the validation of the scholarship program. Majewski et al. (2013) support this indication due to fragmented administration in the implementation of the scholarship program in Indonesia leads to many obstacles in monitoring and evaluating the program, so that has low accountability when the system was not well-developed. Finally, the proportion between actual recipients in the PIS program and its coverage program is the highest compared to other programs. The design of universal coverage for health leads the provider of the program to validate the recipients with the database of non-poor who pay the insurance of health.

Interestingly, Table 5 and Table 6 depict the effectiveness of targeting based on the pattern of non-recipients' program among the vulnerable poor and inclusion error in the non-poor population. The trend of exclusion error in Table 5 increases following the rise of expenditures, but the proportion of non-recipients in the first and second decile is around $20 \%$. It supports the above argument that extreme poor is difficult to reach.

Table 5. The Percentage of Non-Recipients by Percentile Expenditure

\begin{tabular}{lcccc}
\hline Rank of Expenditure & Raskin & PKH & PIP & PIS \\
\hline Decile 1 & $19.13 \%$ & $22.60 \%$ & $24.70 \%$ & $23.77 \%$ \\
Decile 2 & $23.39 \%$ & $24.35 \%$ & $24.72 \%$ & $24.60 \%$ \\
Decile 3 & $26.75 \%$ & $25.61 \%$ & $25.34 \%$ & $25.19 \%$ \\
Decile 4 & $30.73 \%$ & $27.43 \%$ & $25.23 \%$ & $26.44 \%$ \\
\hline
\end{tabular}

Table 6 illustrates that the richest, people whose expenditures in the decile ninth and tenth, also receive the social transfer programs; even though the trend declines following the increase of wealth. It suggests that scaling up the coverage of program from the poverty line approach to vulnerable poor (population of the bottom $40 \%$ of income) has not implemented well regarding the pattern of inclusion errors that reach the decile fifth until decile tenth.

Table 6. The Percentage of Inclusion Error by Percentile Expenditure

\begin{tabular}{|c|c|c|c|c|}
\hline Rank of Expenditure & Raskin & PKH & PIP & PIS \\
\hline Decile 5 & $23.75 \%$ & \multicolumn{3}{|c|}{$30.25 \% 27.89 \% 22.87 \%$} \\
\hline Decile 6 & $21.81 \%$ & \multicolumn{3}{|c|}{$26.05 \% 23.97 \% 20.98 \%$} \\
\hline Decile 7 & $20.30 \%$ & \multicolumn{3}{|c|}{$19.42 \% 19.11 \% 18.74 \%$} \\
\hline Decile 8 & $17.91 \%$ & \multicolumn{3}{|c|}{$15.03 \% 15.38 \% 16.47 \%$} \\
\hline Decile 9 & $11.75 \%$ & $7.55 \%$ & $9.89 \%$ & $2.79 \%$ \\
\hline Decile 10 & $4.48 \%$ & $1.71 \%$ & $3.75 \%$ & $8.14 \%$ \\
\hline
\end{tabular}




\section{Conclusion and Policy Implication}

This paper studies the effectiveness of targeting on social transfer programs in Indonesia employed in Raskin, PKH, PIP, and PIS program. Logit models show the actual performance of miss-targeting each program that classified into exclusion error and inclusion error. The findings suggested that mistake targeting in implementation relies heavily on the urban-rural differences and identity ownership. Still, there is a tendency that the presence of government employees in the household is classified to be the non-poor, so it is difficult to reach the real exact poor beneficiaries. Further, based on urban-rural differences, vulnerable poor living in urban tends to be excluded. Meanwhile, non-poor residing in urban areas has a low probability of being included in the program. Another critical point includes identity administration collection to improve better performance in targeting implementation.

On the other hand, regarding the method of targeting, the criteria of vulnerable poor beneficiaries have mostly covered the determinants of the household characteristics and standards of living. It suggests no error caused by the method of targeting. Moreover, the analysis of miss-targeting performance and coverage programs indicates that the mechanism on delivering the grants has contributed to the effectiveness of the program's implementation. Based on the actual performance, the social safety net performs better compared to the in-kind and cash transfer. However, the challenges are how to fulfill the quota of targeting beneficiaries, mainly to cover the extreme poor as well as reducing recipients from non-poor and ensure the poorest to receive the accessibility to legal identity administration.

In conclusion, the improvement of targeting social transfer programs in Indonesia relies on how to minimize miss-targeting for better cost-effectiveness (Coady, Grosh, \& Hoddinott, 2004; Devereux et al., 2017; Leite et al., 2015), albeit outcome programs have already achieved on behalf of poverty reduction goals (Government of Indonesia, 2018).

\section{Policy Implication}

The first notably issue of miss-targeting social transfer programs suggests that the targeting effectiveness can be as one of consideration in decision making before scaling up social transfer programs. It will help to assist the design and implementation of plans that are better targeting and spent accurately to achieve the output goals. Thus, measurement of effectiveness program suggests considering the miss-targeting evaluation regardless of evaluation of the output program.

Secondly, consider the mechanism of delivering social transfer programs, the policy implies to promote more social safety net like the PIS program. The reason is this program has complementary with non-poor data such as health insurance data as a counter check to the validity of targeting. Further, it suggests the targeting of social transfer programs by centralized and runs out like the private sector, such as Healthcare BPJS, with less political pressure. It would be better if the database on targeting the beneficiaries of social transfer programs is validated by the tax to check the minimum income of each individual or household because the basis of poverty is monetary. Moreover, the analysis of targeting performance suggests caution in employing a mechanism of a delivery program to improve the implementation of the targeting program to promote more social safety net rather than in-kind transfer and cash transfer.

Lastly, put identity as a requirement of the social transfer program has to be re-evaluated. Identity is an effective way to avoid the same person is receiving 
double grants from the same program. Still, it becomes a barrier as well to reach the extremely poor in the case of cash transfer and out of the pocket expenditure. The suggestion would be to conduct a specific program to reach the extreme poor because most social transfer programs could not reach them.

\section{References}

Akita, T., \& Pirmansah, A. (2011). Urban inequality in Indonesia (Working Paper 04: Economics and Management Series, IUJ Research Institute)

Alatas, V., Banerjee, A., Hanna, R., Olken, B. A., \& Tobias, J. (2012). Targeting the poor: Evidence from a field experiment in Indonesia. The American Economic Review, 102(4), 1206-1240.

Alatas, V., Banerjee, A., Hanna, R., Olken, B. A., Purnamasari, R., \& Wai-poi, M. (2019). Does Elite Capture Matter? Local Elites and Targeted Welfare Programs in Indonesia. In AEA Papers and Proceedings (pp. 334-339). https://doi.org/10.1257/pandp.20191047

Coady, D., Grosh, M., \& Hoddinott, J. (2004). Targeting of transfers in developing countries: review of lessons and experience. Washington DC: World Bank. Retrieved May 27, 2019, from http://documents.worldbank.org/curated/en/464231468779449856/Targ eting-of-transfers-in-developing-countries-review-of-lessons-andexperience

Devereux, S., Masset, E., Sabates-wheeler, R., Rivas, A., Lintelo, D., Devereux, S., Masset, E., \& Sabates-wheeler, R. (2017). The targeting effectiveness of social transfers. Journal of Development Effectiveness, 9(2), 162-211. https://doi.org/10.1080/19439342.2017.1305981

Devereux, S., Masset, E., Sabates-wheeler, R., Samson, M., Rivas, A., \& Lintelo, D. (2015). Evaluating the targeting effectiveness of social transfers : A literature review (IDS Working Paper Volume 2015 No.460, CSP Number 012)

Dunning, C., Gelb, A., Raghavan, S., \& Dc, W. (2015). Birth registration, legal identity, and the Post-2015 Agenda. CGD Policy Paper, 046.

Farrington, J., Sharp, K., \& Sjoblom, D. (2007). Targeting approaches to cash transfers: Comparisons across Cambodia, India and Ethiopia. London: Overseas Development Institute

Government of Indonesia. Undang-Undang Republik Indonesia Nomor 11 Tahun 2009 (Law of the Republic of Indonesia number 11 year 2009) (2009).

Government of Indonesia, \& The National Team for the Acceleration of Poverty Reduction (TNP2K). (2017). Basis Data Terpadu (Unified Database) 2015.

Government of Indonesia, \& The National Team for the Acceleration of Poverty Reductioon ( $\left.\mathrm{TNP}_{2} \mathrm{~K}\right)$. (2018). The future of the social protection system in Indonesia: Social protection for all. Retrieved July 2, 2019, from http://tnp2k.go.id/download/42778181129\%20SP\%20Full\%20Report\%20 ENG-web.pd

Hamilton, C., Blitz, B. K., Hamilton, C., Yarrow, E., Fielder, M., Leone, S., \& Panta, N. (2014). Birth registration and children's rights: A complex story (Plan International Full Report 2014). Retrieved July 7, 2019, from https://www.planusa.org/docs/reports/2014-birth-registration-researchfull-report.pdf 
Hanna, R., \& Karlan, D. (2016). Designing social protection programs: Using theory and experimentation to understand how to help combat poverty. Handbook of Economic Field Experiments, 2, 515-553. https://doi.org/10.1016/bs.hefe.2016.07.002

Harbitz, M., \& Tamargo, M. del C. (2009). The significance of legal identity in situations of poverty and social exclusion: The link between gender, ethnicity, and legal identity (Technical Note, 2009). Washington, DC: InterAmerican Development Bank. Retrieved July 7, 2019, from https://publications.iadb.org/en/significance-legal-identity-situationspoverty-and-social-exclusion-link-between-gender-ethnicity

Holzmann, R., \& Jorgensen, S. (1999). Social protection as social risk management: Conceptual underpinnings for the social protection sector strategy paper (Social Protection Discussion Paper series No. SP 9904). Washington, DC: The World. Retrieved March 29, 2019, from http://documents.worldbank.org/curated/en/348031468739766346/Social -protection-as-social-risk-management-conceptual-underpinnings-for-thesocial-protection-sector-strategy-paper

Hossain, A. (2010). Age in grade congruence and progression in basic education in Bangladesh. Paper based on the Consortium for Research on Educational Access, Transitions \& Equity (pp. 1-2). Retrieved July 7, 2019, from https://files.eric.ed.gov/fulltext/ED517694.pdf

Leite, P., Stoeffl, Q., \& Kryeziu, A. (2015). Targeting Effectiveness of Safety Net Programs in Senegal. In B. Mills \& C. del Ninno (Eds.), Safety nets in Africa: Effective mechanisms to reach the poor and most vulnerable (pp. 213-236). https://doi.org/10.1596/978-1-4648-0435-9_ch9

Majewski, C., Ringoringo, A., Soeharno, R., Umaedi, Sumertajaya, I. M., \& Haloho, J. F. (2013). Support for poor families in meeting the personal costs of basic education (Report of The Education Sector Analytical and Capacity Development Partnership - ACDP 006). ADB Publication. Retrieved July 18, 2019 , from https://www.adb.org/sites/default/files/publication/176605/ino-supportpoor-families-basic-education.pdf

Norton, A., Conway, T., \& Foster, M. (2001). Social protection concepts and approaches: Implications for policy and practice in international development. Overseas Development Institute, 43(February), 1-76.

Ravallion, M. (2009). How relevant is targeting to the success of an antipoverty program? The World Bank Research Observer, 24(2), 205-231.

Sabates-Wheeler, R., Hurrell, A., \& Devereux, S. (2015). Targeting social transfer programmes: Comparing design and implementation errors across alternative mechanisms. Journal of International Development, 27, 15211545. https://doi.org/10.1002/jid

Satriawan, E., \& Shrestha, R. (2018). Mistargeting and regressive rake up of the Indonesian rice subsidy program. Asian Economic Journal, 32(4), 387-415. https://doi.org/10.1111/asej.12164

Sharif, I. A. (2009). Building a targeting system for Bangladesh based on proxy means testing (Social Protection and Labor Discussion Paper, No. SP 0914). Washington, DC: World Bank. Retrieved July 7, 2019, from 
http://documents.worldbank.org/curated/en/321521468014446788/Buildi ng-a-targeting-system-for-Bangladesh-based-on-proxy-means-testing

Slater, R., Holmes, R., Farrington, J., \& Harvey, P. (2007). Cash transfers and their role in social protection. Overseas Development Institute, 44(August 2006), $7-11$.

Stoeffler, Q., Mills, B., \& Del, C. (2016). Reaching the poor: Cash transfer program targeting in Cameroon. World Development, 83, 244-263. https://doi.org/10.1016/j.worlddev.2016.01.012

Sumner, C. (2015). Indonesia's missing millions: Erasing discrimination in birth certification in Indonesia (CGD Policy Paper 064, June 2015). Washington, DC: Center for Global Development. Retrieved July 7, 2019, from https://www.cgdev.org/sites/default/files/CGD-Policy-Paper-64-SumnerMissing-Millions.pdf

Tjiptoherijanto, P., \& Remi, S. S. (2001, July 4-6). Poverty and inequality in Indonesia: Trends and programs. Paper presented at International Conference on the Chinese Economy "Achieving Growth with Equity" in Beijing. Retrieved July 2, 2019, from https://pdfs.semanticscholar.org/8d9c/82680ef1 1c97aOeff72fdae4cacaa2b5 8167.pdf

Tohari, A., Parsons, C., \& Rammohan, A. (2017). Targeting poverty under complementarities: Evidence from Indonesia's unified targeting system (Dicussion Paper Series IZA DP No. 10968). IZA Institute of Labor Economics. Retrieved July 4, 2019, from http://ftp.iza.org/dp10968.pdf

World Bank. (2016). Identification for Development (Strategic Framework, ID4D). Retrieved July 7, 2019, from http://pubdocs.worldbank.org/en/179901454620206363/Jan-2016-ID4DStrategic-Roadmap.pdf 